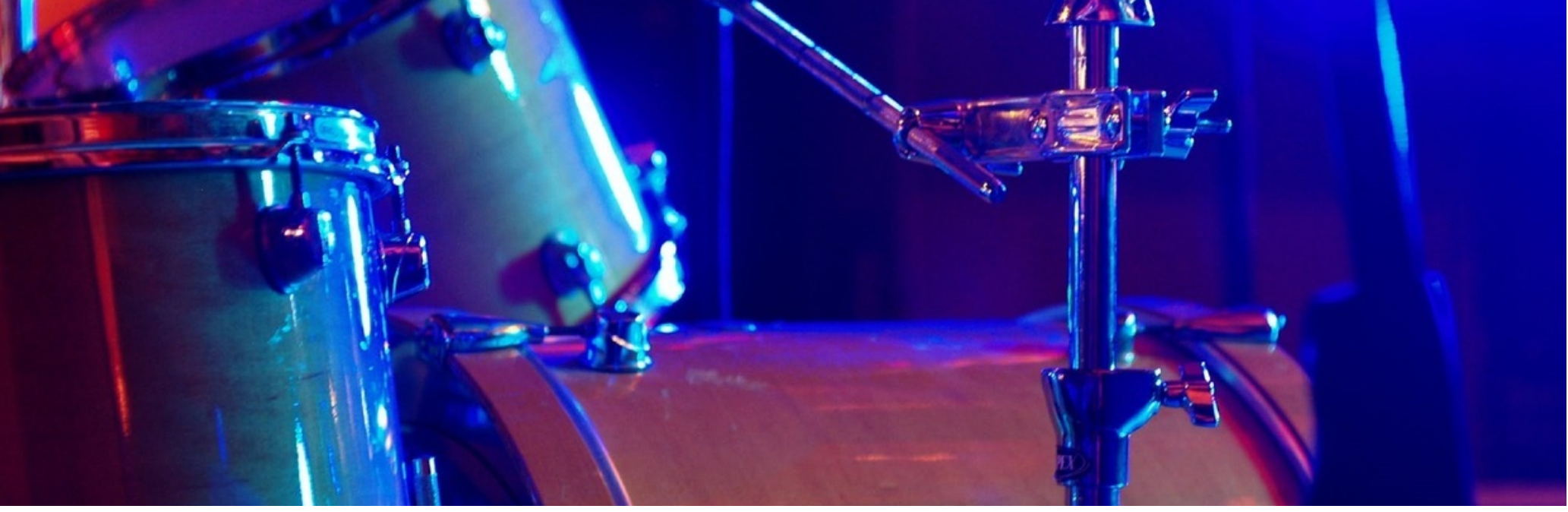

“If You Speak It, You Play It"

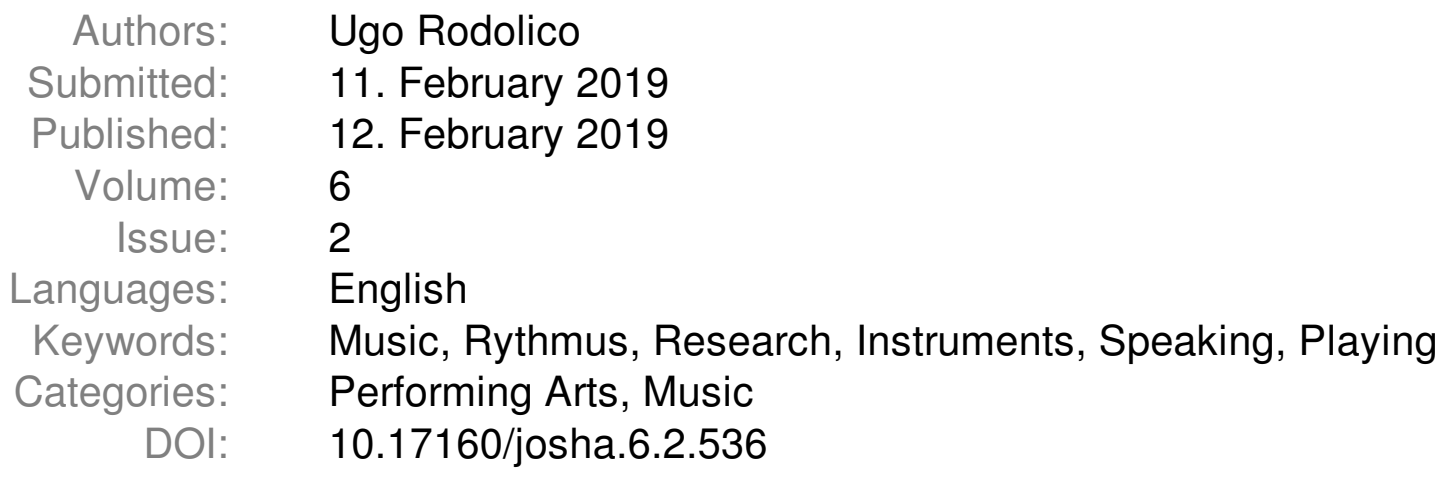

\title{
Abstract:
}

The central idea of my thesis is to establish a close relationship between specific drumming technique, which is based today on the study of the rudiments seen earlier, and a more general method of learning rhythm that uses strategies and suggestions from outside classical music theory, which is understood solely as a division system. The Greeks described rhythm with words that always point to a deep relationship between movement and the temporal arts. The fundamental distinction has always been between arsis and thesis, that is, between momentum and support. The original meaning of these two words had to do with the alternating struggle of all movements of the body against gravity; momentary impulses always followed by relapses and supports that originated new impulses. 


\section{If You Speak It, You Play It}

\section{Rhythm and Language}

\section{Ugo Rodolico}

\section{In Search of a Rhythm Methodology}

The central idea of my thesis is to establish a close relationship between specific drumming technique, which is based today on the study of the rudiments seen earlier, and a more general method of learning rhythm that uses strategies and suggestions from outside classical music theory, which is understood solely as a division system.

The Greeks described rhythm with words that always point to a deep relationship between movement and the temporal arts. The fundamental distinction has always been between arsis and thesis, that is, between momentum and support. The original meaning of these two words had to do with the alternating struggle of all movements of the body against gravity; momentary impulses always followed by relapses and supports that originated new impulses.

By extension, the two terms have been related to the highest and lowest pitch of the voice, "This sequence of surges and rest organises itself into what the ancients called a foot" ${ }^{1}$. A foot was a grouping of syllables forming a strong unit from the beat of the foot of the singer or storyteller or of the flute player who directed the choir. In ancient Greece, music was inseparable from poetry and the rhythm was the common connection between the two temporal arts. In poetry the meter was governed by a sequence of long and short syllables that determined the alternation of strong

\footnotetext{
${ }^{1}$ Fraisse P., Psychologie du temps (Psychology of Time), Rome, Armando Editore, 1996, p.99.
} 
and weak rhythms. On the other hand, music adopted the same principles as poetry: musical rhythm was born when there were two or more notes or syllables, long and short.

These observations suggest a primary element that has always been combined with rhythm, which is language, understood as a movement of the speech organs which have the ability to emit cries, sounds and words.

However, there is another consideration: a "different" music theory might be one that does not observe a time module that is repeated for a duration that is necessarily divided equally, such as in the modern measure with

its subdivisions, but rather as a unified group of longer and shorter elements, resulting from the sum of parts that may have different durations and forming a sequence built, a bit like it was for the ancients, on the addition of the feet, i.e. autonomous and unitary rhythmic motifs.

In this chapter I will be taking a look at some methodologies, particularly the Schulwerk methodology by Carl Orff, which have placed movement and language at the heart of a learning process. In the fifth section, I will be exploring some later contributions to Orff's approach. In the sixth section, I will be examining rhythmic grouping as a perceptual phenomenon. In the next chapter I will be presenting a series of practical proposals aimed at the correct playing of the drum rudiments using a "different" way that re-elaborates some of the theoretical premises set forth herein.

\section{The Dalcroze Method}

One of the first methodologies in rhythmic education and modern and innovative music was created by Émile Jaques-Dalcroze, a Swiss musician, composer and pedagogue working in the early 20th century. He developed the Dalcroze Eurhythmics.

In his method, the appropriation of any musical element in terms of analysis, decoding and production is possible only through the experience of the movement.

Dalcroze sensed the unity that exists between body, mind and the emotions. His classes were always collective and consisted of a series of physical exercises designed to develop inner listening 
and improvisation and create a certain closeness among participants by establishing a relationship of mutual trust within a group.

Dalcroze can rightly be considered to be the first to have laid the foundation for an educational and rehabilitative use of music and movement.

\section{Carl Orff}

Carl Orff is, in a sense, the heir to Dalcroze's ideas. Born in Munich, Germany on 10 July 1895, he can be considered one of the most successful German composers of his time. He studied at the Academy of Music in Munich with Anton Beer-Walbrunn and Herman K. Y. Zilcher, specialising later under the guidance of Heinrich Kaminskl.

In the meantime, he devoted himself to orchestra conducting and to the study of music from the past, among other things overseeing the revision of operas by Monteverdi. He began his educative activities as a teacher of composition. As a composer, he had his first big success in 1937 with Carmina Burana for choir and orchestra, using 13th century Latin, French and German texts taken from a codex by Beuron.

In the wake of this successful composition came Catulli Carmina in 1943, based on Latin texts by Catullus, and Trionfo di Afrodite in 1955 from Greek and Latin texts by Catullus, Sappho and Euripides. The three compositions were grouped together in a single triptych entitled Trionfi. In his output, the vocal genre generally prevails over the instrumental; in addition to the abovementioned works, he also wrote oratorios, cantatas, hymns and choral compositions. His instrumental music, which is rare and composed for an orchestra, all belongs to the period before Carmina Burana.

In 1924, together with his wife Dorothea Gunter, he founded a school inspired by the Dalcroze method, for the teaching of rhythmic gymnastics, music and ballet; it was during this period that he dealt with the problems of teaching and conceived the idea of Schulwerk as a set of processes that would help children become familiar with the most simple and direct musical expressions. 


\section{Schulwerk}

Schulwerk (also known as the Orff Approach) is presented as a reworking of Dalcroze's Eurhythmics: Orff tried to deepen the relationship between music and movement not only in terms of a rhythmic - expressive education which was mainly corporal and based on mime, but also wholly musical; all through the use of rhythmic and melodic percussion instruments which were easy to use (xylophones, metallophones, drums etc.) so that the principle of improvisation that Dalcroze had restricted exclusively to the piano could be extended to a broader range of instrumentation. The Orff Approach is rooted in a vision of education that recognises its links with popular language, with the essential rhythms of life and with the life of nature. As derived from a proposal by Orff, the role of the teacher is to propose, activate, stimulate experience, without any special attention to the enhancement of those skills possessed but rather gradual learning reached intuitively.

Orff did not write down his method but left the task to Fritz Reusch, author of Grundlagen und Ziele des Orffs-Schulwerks ("The Foundations and Purposes of Schulwerk by Orff”) and Wilhelm Keller, author of Einführung in "Musik für Kinder" (Introduction to "Music for Children").

Fritz Reusch describes Orff's educational conception as follows:

“[...] The background and the purpose of Orff's Schulwerk cannot be conveniently illustrated by the analysis of the music, or from historical and folkloric parallels to the musical styles. [...] Its sources date back to our origins and should be considered as a force of pure and indestructible authenticity. It is about that inner strength [...] which through the centuries has nourished song, games, the wisdom of the proverbs of our people, and which, although it seemed buried as a result of wrong-headed ways of living and teaching, will have to come back into use. The possibilities of musical education in our time thus consist in being able to go back [...] to the experience and knowledge of fairy tales, sagas, of childhood and popular songs and their indestructible values [...] A crucial support in this direction is undoubtedly provided by Schulwerk, because in Schulwerk Orff was able to mix the primary (but not primitive) sound world of the child and that of the keen amateur, which is "pedagogically framed" within certain forms of improvisation [...] The truth and the importance of fairy tales remain, due to the laws of nature, the child's heritage, despite all the illuminations [...] Indeed in the technological era these deep reasons need to be cultivated and maintained in a child if in adulthood we do not want to encounter serious mental and nervous disorders [...] The old popular sayings, ancient nursery rhymes (in all cultures, all the way back to the wisdom of the Chinese) will therefore always remain important, 
because in them language is constructed and interpreted based on the primitive elements, the sound or the word and they are not rigidly set down in letters and words. Rhythm and sound gave them life by translating mimed and gestural movements into bodily actions. This applies primarily to singing-playing and singing-dancing. Rhythmic word games joined with movements (beating a drum, riding, mimicking various activities and trades) combine the tongue and the limbs through the clapping and stamping of the feet, so they can achieve what many so-called "fun" musical exercises often fail to achieve: true joy and enthusiasm." 2

Orff speaks about elementary music by defining the concept: "elementary music is never solely music, it is linked to movement, dance and speech. The process used is based on things that children like to do, such as reciting nursery rhymes, singing, dancing, beating out rhythms with their hands and with their whole body. The rhythms are made as an "ostinato", that is, they are repeated equally: the overlapping of several of them, played by different instrumentalists, creates the ensemble music passages." 3

The starting point in Orff Approach teaching lies not in facts or in musical elements, but in language. As revealed by a German scholar Ludwig Wismeyer, human speech occupies an important place throughout school: in fact it is used in all subjects, but in the effort to turn it into a precise tool in semantic terms, in the effort to move more deeply towards its conceptual possibilities, we neglect to strengthen it as an element of human expression, in the sense of form and sound.

Orff says: "[...] at the beginning of each musical exercise, whether melodic or rhythmic, there is a linguistic exercise." 4

It therefore harks back to one's mother tongue. From the traditional heritage of nursery rhymes, popular sayings, and proverbs by peasants he draws the most simple forms and the first formulas of rhythmic patterns, and offers the model of first melodic creations. From the analogy of spoken phrases and melodies come first purely rhythmic phrases and then rhythmic-melodic phrases.

\footnotetext{
${ }^{2}$ BENINCASA A., Il metodo Orff-Schulwerk e il ruolo formativo del linguaggio musicale nell'era del virtuale, secondo i parametri applicativi del [WGS], (The Orff-Schulwerk method and the formative role of the musical language in the virtual age, according to the application parameters of the [WGS]), degree thesis in education and technological culture at Suor Orsola Benincasa University, Naples, 2006-2007 academic year, p.15.

${ }^{3}$ Ibid, p. 15.

${ }^{4}$ Ibid, p. 19.
} 
In 1950 began the publication of Musik für Kinder, a collection in five volumes containing sung and played materials, ideas for rhythmic and melodic improvisation, mainly derived from work done by Orff and by Keetman during transmissions for schools on Bavarian radio for five consecutive years starting in September 1948.

Carl Orff at first insisted on the methodological necessity of proceeding in an unsystematic manner, going from one passage to another, without bothering to follow the order that is naturally placed by the sequence of volumes and, within each volume, he preferred to talk about rhythms rather than rhythm as a whole. Orff himself writes, in the book "Schulwerk - Elementary Music" (the third in the autobiographical series "Carl Orff and his work - Documents" published by Schneider, Tutzing): "Unfortunately, rhythmic-melodic practice, which only aims to offer suggestions and materials, has been falsely interpreted in various ways and used as a textbook, on the basis of which you can learn and perform one piece after another."

The type of classification of the material, which shows a more anthological than pedagogical approach, was the origin of the belief, still widespread, that practicing Orff Approach pedagogy meant learning and performing the pieces they contain, encouraging their classification as a "method", that is, as a sum of progressive operational experiences tending to lead to certain levels of skill, precisely what the author wanted to avoid at all costs.

The German volumes of Orff-Schulwerk are often directed more at a "child player" than a "child creator"; but beyond this inevitable consequence that any material - even if designed to provide creative suggestions - suffers at the moment it is printed, Musik Für Kinder turns out to be a truly useful compendium of tips and advice that outlines, especially in the first volume, some interesting rhythmic proposals to be implemented with the use of the different ways of playing them.

First of all with the voice: rhythmic emission of words, phrases, but also onomatopoeia. Then with the hands and feet. The hands can be clapped together or on the thighs; you can snap your fingers, or stamp your feet on the floor. You can also, with these "bodily" means, create short compositions (the famous body-percussion of today) which highlight different sounds; these are basic rhythmic patterns that can be implemented with simple percussion instruments, others with 
idiophone instruments, and you can make rhythmic canons, or improvise a call-and-response exercise.

Finally, of course, you can base the rhythmic accompaniments to songs on the concept of ostinato: a single rhythmic formula composed of one or two, but rarely more, beats that develops throughout an entire song, and never varies (I would highlight a parallel here with the practice of drum rudiments that can also be considered as a series of musical exercises in the form of an ostinato).

\section{Word-gesture-sound 5}

In his thesis on Orff's Schulwerk, Marcello Napoli, with whom I have worked for a number of years, explores the process used by Orff from a neurocognitive, psycho-pedagogic, artistic and cultural perspective.

Some of his ideas are extremely interesting. According to Napoli, the method indicated by Orff combines three elements: speaking, gesture and sound. Some rhymes are used that are associated with movements in space (locomotor-related) and body movements (proprioception) and are subsequently expressed on a set of rhythmic and melodic instruments.

While it is true that rhythm is, as Plato said, "order in movement" (Laws, 665a) and if, as some music psychologists now claim, we are faced with a rhythmic event whenever "[...] two or more events are present in a regular determined pulse," 6 it is equally true that language, made up of words, has in itself rhythmic elements that can be arranged in a regular pulse, as we have seen.

According to P. Fraisse "Man does not have his own body and his own voice from the outset. It is not unreasonable to think [...] that the human neuromuscular organisation favours the repetition of identical movements [...] P. Emmanuel argues that a verbal gesture corresponds to a physical gesture [...] Let us ask ourselves the question posed by J. Chailley (1971): is rhythm born

\footnotetext{
${ }^{5}$ NAPOLI M., Psicopedagogia della metodologia Orff-Schulwerk (Psycho-pedagogy of the Orff-Schulwerk methodology), Rome, www.orffitaliano.it/orff.htm, 2003, p.11.

${ }^{6}$ Sloboda J., La mente musicale (The Musical Mind), Il mulino, 2000, Bologna, p. 310.
} 
in a verbal context or in a gestural context? But then have they ever actually been separate? Would not it be better to seek what belongs more particularly to each of the activities from the moment they were related?" 7 .

The "rhythmic verbalisation" through nursery rhymes brings out the rhythmic elements of a word or phrase by inducing a motor response with gesture which are sometimes proprioceptive. One example can be seen from the more natural "swing" that certain songs can trigger in children as early as 18 months of age.

Cognitive psychology argues that the language of intentionality has some features that turn the verbal event into a psychomotor support. A linguistic exercise, such as a nursery rhyme or a tongue twister, constitutes a valid technical prerequisite for a musical gesture.

On the other hand, in non-European music, such as that of Arabic or Indian culture, where the rhythm is organised according to formulas that Sachs (1953) called "additive" (as opposed to the European ones defined as "divisive"), the physical-sound and gestural-verbal levels have always been intimately connected.

Regarding Indian rhythmic culture, Anna M. Freschi notes that "[...] The use of onomatopoeic syllables that relate to percussive sounds [...] function as a sort of 'oral notation' that helps to differentiate the types of sound and, at the same time, by clarifying the internal structure in order to give shape to and then to memorise the groupings. The same function is performed by the accompanying gestures [...] which mark the interior segments of each cycle, with a similar function to that developed in the melodic field by chironomy in the Western tradition" 8

Very often, as I have observed in my teaching experiences, a meaningless chant containing onomatopoeic sounds closely related to the timbre of a drum or a particular rhythmic sequence, is much more engaging for a child than a cadenced narration. This is because the rhythm of the words has a pure appeal beyond any semantic content.

\footnotetext{
${ }^{7}$ FrAISSE P., Psychologie du temps (Psychology of Time), op. cit., p.99.

${ }^{8}$ FresCHI A.M., Movimento e misura. Esperienza e didattica del ritmo (Motion and Measurement. Experience and Teaching of Rhythm), Turin, EDT, 2007, pp. 104-105.
} 
Even the prosodic aspect, i.e. everything related to the accentuation and melodic flow of a sentence, contributes both to reinforcing a child's motivation while chanting a nursery rhyme and to creating a direction and a phraseological structure in the same nursery rhyme: a parabolic prosodic inflection with a tone of voice that initially rises to a peak and is slowly lowered easily identifies the opening and closing of a sentence.

A rhythmic nursery rhyme will then have within it:

- $\quad$ A marked prosody, almost exaggerated

- $\quad$ Very strong accents

- Well-articulated sounds

- Well-marked and organised rhythm

- $\quad$ Inherent repetitiveness that reinforces and facilitates memorisation

Proprioception is the second stage of learning music. It is a natural and immediate channel, since the body acts as both instrument and instrumentalist. The impact of the gesture-sound (clapping, slapping the legs or chest, etc.) causes the rhythm of the word to be translated in two ways: a motor construction, linked to a voluntary act, albeit an imitative one, and a sound construction, according to which the sound becomes a rhythmic confirmation.

Sound, finally, becomes the "litmus test" of a verbal and motor path. Napoli argues that "[...] we need to start with an assumption: sound comes from movement. Having said that, the next consideration is that, when we perceive a sound, our auditory system begins a movement. The sound wave that is produced from the source, passes through the outer ear to reach the ear canal, inside which the tympanic membrane transmits the movement to the ossicles, the last of which, the stirrup, supported on the oval window of the cochlea, produces a wave in the cochlear fluid, distorting the basilar membrane on which the hair cells are found. These, in turn, have the task of sending nerve impulses to the brain, thus turning them into electrical impulses. This is, in short, 
the auditory pathway of the sound wave, in which the brain is the last stop, charged with the task of recognising and cataloguing the stimulus based on its characteristics.

This is what happens for each individual sound stimulation. Now it is easy to understand why, under certain circumstances, our body seems unable to control itself when it perceives captivating and exciting sounds, such as some tribal rhythms performed on drums, or some Latin American rhythms. At the opposite end are the motor stimulations that our body receives when the musical induction is for example Tai Chi, or sweet soothing lullabies.

What is described and the close relationship that exists between the sound phenomenon and the motor response is defined (by the various schools of psychology and neuro-physiology) as "Isomorphism". In other words, the sound wave that is created in our auditory system causes a direct reconstruction of itself from the neuro-muscular point of view. If we propose, for example, to a group of children to move along with a rhythmic verbal stimulation enunciating the word "takète", we will see a group of small robots interpret it in a mechanical way. The opposite reaction would occur if it all happened under verbal induction with the word "maluma", in this last case their movements would become round, sinuous and controlled." 9

\section{The Rhythmic Group}

In the previous chapter we saw that the drum rudiments begin as characteristic rhythmic fragments and that certain names, such as the Seven Stroke Roll, suggest a kind of grouping that identifies them.

On the other hand, the psychology of rhythm tells us that, in certain conditions of sequences, all the rhythmic stimuli are perceived as if they were grouped, and the repetition of these groups gives rise to the perception of rhythm.

If in a quiet environment we hear the ticking of a clock, we perceive them grouped in twos or threes, rarely fours (so much so that in general we say: "The tick-tock of a clock", identifying a

\footnotetext{
${ }^{9}$ NAPOLI M., Psicopedagogia della metodologia Orff-Schulwerk (Psycho-pedagogy of the Orff-Schulwerk methodology),op. cit., p.8-9.
} 
group of two elements with two different words), even if the sequence of the chimes is perfectly regular.

This is known as subjective rhythmitisation since there is no factor related to the number of chimes which results in any grouping.

Then two equally subjective events occur related to the grouping perceived. First of all, the interval between two sequential groups appears longer than that between the elements of the group (when there is physical equality); secondly, the first element of the group seems more accentuated than others. The rhythmitisation would be objective if a periodic interval longer than the others had created a pause or if one element out of every two or three was actually accentuated.

It appears that grouping, whether it is subjective or objective, is a key feature of perception. And this occurs both for spatial forms (according to the laws of Gestalt theory) and for temporal forms, with the attendant differences.

In space it is enough for there to be proximity because some elements constitute a form (Wertheimer's proximity principle).

In the temporal field it is necessary to recognise that our perception is not a simple sequence of moments, as with the images of a film, but that there is a "psychological present in which subsequent elements are organised in a series of forms" ${ }^{10}$.

This psychological present (or, in other words, our short-term memory), allows a global perception of the sequence and allows the identification of rhythmic structures in the same sense in which we speak of an iamb or a dactyl.

The grouping criterion is critical to perceive complex rhythmic and musical structures. In objective rhythmitisation, it is observed that subsets intervene that allow us to multiply the number of elements we have perceived into a relative unit.

In the process of learning drum rudiments, it is very important to perceive every stroke not as a separate entity but as an element of a larger or smaller group. Theoretical assumptions and my experience have led me to believe that the use of language in rhythmic practice helps in

\footnotetext{
${ }^{10}$ Fraisse P., Psychologie du temps (Psychology of Time), op. cit., p.60.
} 
strengthening the subjective rhythmitisation, thus making it objective. In the next chapter we will see how that can occur. 